\title{
Source apportionment and spatial variability of PM2.5 using measurements at five sites in the Netherlands
}

\author{
D. Mooibroek ${ }^{\mathrm{a}}$ \\ M. Schaap ${ }^{b}$ \\ E.P. Weijers ${ }^{c}$ \\ R. Hoogerbrugge ${ }^{a}$
}

\footnotetext{
${ }^{a}$ Centre for Environmental Monitoring, National Institute of Public Health and the Environment (RIVM), Bilthoven, The Netherlands

${ }^{\mathrm{b}}$ TNO Environment and Geosciences, Department of Air Quality and Climate, Utrecht, The Netherlands

${ }^{c}$ Energy Research Centre of the Netherlands (ECN), Petten, The Netherlands
} 


\title{
Source apportionment and spatial variability of $\mathrm{PM}_{2.5}$ using measurements at five sites in the Netherlands
}

\author{
D. Mooibroek ${ }^{a, *}$, M. Schaap $^{\text {b }}$, E.P. Weijers ${ }^{c}$, R. Hoogerbrugge $^{a}$

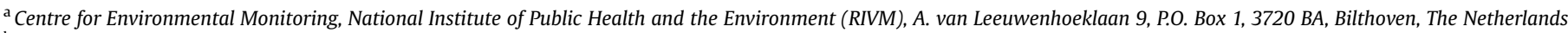 \\ ${ }^{\mathrm{b}}$ TNO Environment and Geosciences, Department of Air Quality and Climate, P.O. Box 80015, 3508 TA Utrecht, The Netherlands \\ ${ }^{\mathrm{c}}$ Energy Research Centre of the Netherlands (ECN), P.O. Box 1, 1755 ZG Petten, The Netherlands
}

\section{A R T I C L E I N F O}

\section{Article history:}

Received 9 December 2010

Received in revised form

6 April 2011

Accepted 4 May 2011

\section{Keywords:}

Source apportionment

$\mathrm{PM}_{2.5}$

Positive matrix factorization

PMF

Multilinear engine

ME-2

Spatial variability

\begin{abstract}
A B S T R A C T
The Netherlands is considered one of the hotspot areas in Europe with high concentrations of particulate matter (PM) and may not be able to meet all standards for $\mathrm{PM}_{2.5}$ in time with current legislation (Matthijsen et al., 2009). To improve our understanding of the composition, distribution and origin of $\mathrm{PM}_{2.5}$ in the ambient air an intensive one-year measurement campaign (from August 2007 to September 2008) was performed at five locations in the Netherlands. The five sites consist of three rural background sites, one urban background site and one curbside site. We have applied source apportionment using Positive Matrix Factorization (EPA-PMF) on the pooled data from the five sites to identify and quantify the most relevant source contributions and their spatial variability to $\mathrm{PM}_{2.5}$ in the Netherlands. The results of this study are compared to a full mass closure analysis of the data. Using EPA-PMF we could identify seven unique sources for the $\mathrm{PM}_{2.5}$ fraction: nitrate-rich secondary aerosol, sulphate-rich secondary aerosol, traffic and resuspended road dust, industrial (metal) activities/incineration, sea spray, crustal material and residual oil combustion. Wind directional analysis was used to determine the possible locations of the identified sources. On the five locations secondary inorganic aerosol (SIA) is responsible for the largest contribution. The contribution of SIA to the total $\mathrm{PM}_{2.5}$ mass is largely constant at all used sites. This indicates these sources are common sources which behave like area sources and affects each site. The largest contribution of the traffic and resuspended road dust profile was found at the curbside site. Using combined data from five measurement sites provides focus on the common sources (e.g. SIA) affecting all locations.
\end{abstract}

(C) 2011 Elsevier Ltd. All rights reserved.

\section{Introduction}

While air quality in Europe has improved substantially over the past decades, air pollution still poses a significant threat to human health (EEA, 2007). Health effects of air pollution are dominated by particulate matter (PM), both $\mathrm{PM}_{2.5}$ and $\mathrm{PM}_{10}$. As the long-term exposure to PM is posed to cause a substantial reduction in life expectancy, it is thought to have a larger significance to public health than the short-term effects (Brunekreef and Holgate, 2002). However, short-term exposure to PM has frequently been associated with inflammatory reactions in the lung, respiratory symptoms, adverse effects on the cardiovascular system and increases in hospital admissions and mortality (e.g. Lippmann and Chen, 2009; Brunekreef and Holgate, 2002). In the new EU Directive (2008/50/ EC) on ambient air quality and cleaner air for Europe (EU, 2008) an

\footnotetext{
* Corresponding author. Tel.: +31 30274 2289; fax: +31 302287531.

E-mail address: dennis.mooibroek@rivm.nl (D. Mooibroek).
}

annual mean $\mathrm{PM}_{2.5}$ concentration of $25 \mu \mathrm{g} \mathrm{m}{ }^{-3}$ has been set as target value to be met in 2010 and as limit value to be met in 2015 . The new directive further introduces additional $\mathrm{PM}_{2.5}$ objectives, which aim at a 15 or $20 \%$ reduction of the average exposure indicator (AEI). To develop mitigation strategies to meet these targets and to reduce the concentrations of $\mathrm{PM}_{2.5}$ in general one needs to establish the origin of particulate matter.

In order to understand and describe particulate matter at least two different modelling strategies exist, chemistry transport models and statistical receptor models. Chemistry transport models can be used to provide a detailed source apportionment in space and time. In theory they cover the whole range from source to receptor and are superior in the ultimate understanding of processes involved. Despite a general satisfactory model performance, important gaps in knowledge concerning several sources and formation routes cause these models to systematically underestimate PM levels (Stern et al., 2008), which limits their use for a complete source apportionment. The alternative, statistical receptor methods, can be a useful complementary for example 
when (emission) input data are missing or inaccurate but also as cheap independent confirmation of the results of the quite complex transport models. Receptor-oriented models, based upon mass balance analysis with mass conservation, are generally used to assist in the identification of sources and the apportionment of observed pollutant concentrations to these sources. Several types of receptor models are available and for a review we refer to Viana et al. (2008). The main difference between these types of receptor models is the degree of knowledge required about the pollution sources prior to the application of these models. For instance, the Chemical Mass Balance (CMB) model assumes that the composition profile for all relevant sources is known, a situation that is hardly met in reality. In case the number of sources and their profiles are unknown factor analysis, e.g. Positive Matrix Factorization (PMF) or Unmix, can be used to find both the profiles and their contributions based upon a set of samples on the basis of observations (internal correlations) at the receptor site alone (Hopke, 1991; Paatero and Tapper, 1994). Such models apply physical constraints, e.g. limiting to non-negative source contributions, and use different algorithms to solve the problem (Paatero et al., 2002; Viana et al., 2008). PMF has the advantage of scaling each data point individually by using an uncertainty matrix, so data with a higher precision has a larger influence on the solution (Hopke, 2003).

The Netherlands is considered one of the hotspot areas in Europe with high concentrations of PM and may not be able to meet all standards for $\mathrm{PM}_{2.5}$ in time with current legislation (Matthijsen et al., 2009). To improve our understanding of the composition, distribution and origin of particulate matter in the ambient air a new project called the Netherlands Research Program on Particulate Matter (BOP) was started. The research within the Program was facilitated by an intensive, one-year measurement campaign (from August 2007 to September 2008). The aim of this study is to establish the composition of $\mathrm{PM}_{2.5}$ as well as to use source apportionment (PMF) to identify and quantify the most relevant source contributions and their spatial variability to $\mathrm{PM}_{2.5}$ in the Netherlands.

\section{Experiment}

\subsection{Data collection}

For this study $\mathrm{PM}_{2.5}$ filter samplings were obtained at five locations in the Netherlands between 15 August 2007 and 4 September 2008. Filters were collected every second day and half of the filters were analyzed for composition, resulting in 82-115 samples per site for use in PMF and mass closure (Weijers et al., 2011). As the composition of PM varies with region and station type, measurement sites were selected in urban as well as rural background areas (See Fig. 1 and Table 1). The urban background and traffic station were located in the greater Rotterdam area. Three rural background sites (Hellendoorn, $\sim 150 \mathrm{~km}$ from Rotterdam; Cabauw $\sim 50 \mathrm{~km}$ from Rotterdam; Vredepeel, $\sim 100 \mathrm{~km}$ from Rotterdam) were selected. Cabauw provides the rural background for the western part of the country whereas Hellendoorn and Vredepeel were selected to add information for the eastern part of the country. Vredepeel is characteristic for intensive agricultural activity in its direct surroundings. The urban background site Rotterdam is part of the National Air Quality Monitoring Network (NAQMN). In Rotterdam a street site was also chosen, Rotterdam-Overschie, constituting part of the regional air quality network operated by DCMR. Both sites are located near the Port of Rotterdam, an area that can be considered as an industrialized area with a lot of petrochemical and shipping activities.

The filters were collected according to the reference method described in the European Standards (EN 12341, 1998 and EN 14907,

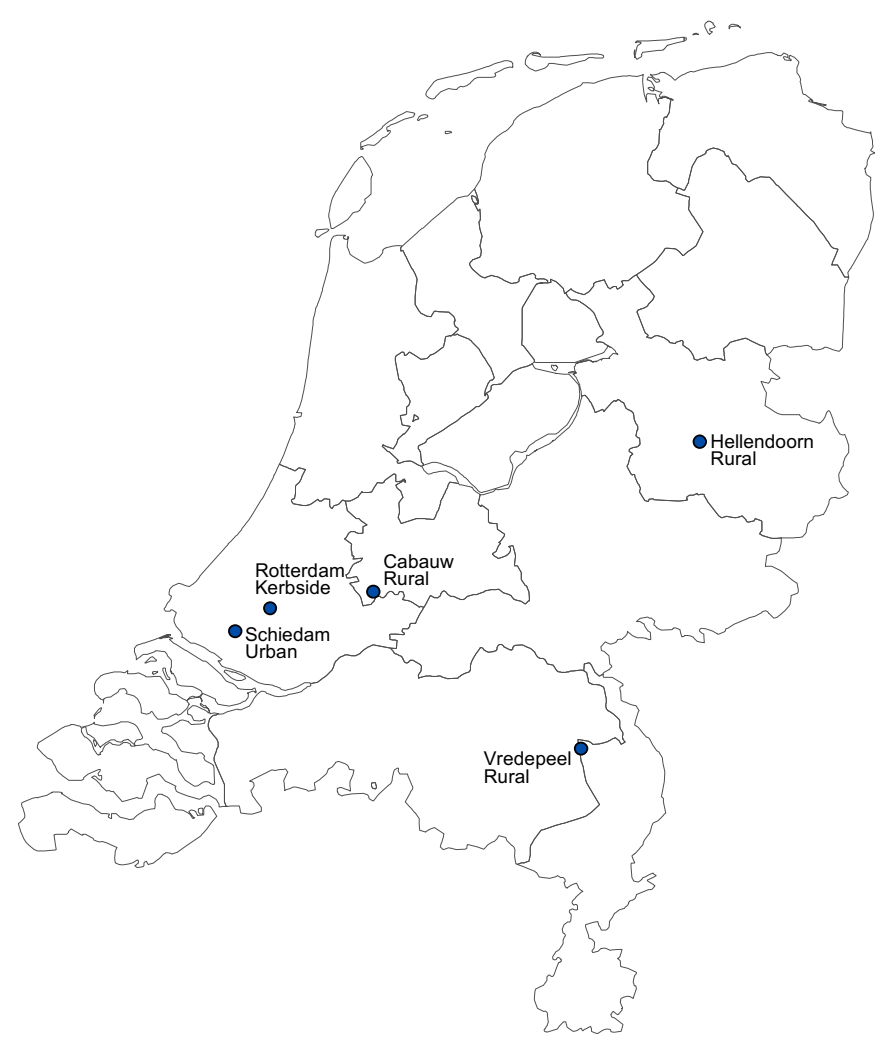

Fig. 1. Location and characteristics of the sampling sites.

2004). The measurement instrument was the SEQ47/50 (Leckel $\mathrm{GmbH}$, Germany). In this study this sequential low-volume system (LVS) uses a flow of $2.3 \mathrm{~m}^{3} \mathrm{~h}^{-1}$. Two of these reference samplers were placed on every site for a pairwise measurement of $\mathrm{PM}_{2.5}$. Two types of filter media, quartz (QMA) and teflon (PTFE), were used. The teflon filters were chosen to quantify silicon in suspended particulate matter. The quartz fibre filter media is the material commonly used for gravimetric studies in the Netherlands. The sampling period was $24 \mathrm{~h}$ and ran from midnight to midnight. The filters were changed once every fortnight. The logistic and operational $(\mathrm{QA} / \mathrm{QC}$, weighing) procedures are those used in the NAQMN network and are described in Schaap et al. (2010), which also contains the details of the acquired database.

Sulphate and nitrate have been measured in aqueous solutions with the Dionex IC25. This system combines an Ion Chromatography System with a conductivity detector and a high performance dual-piston pump into one compact package. Ammonium was analyzed on the AMFIA (ECN, Petten, The Netherlands). This analysis system is based on the selective diffusion of $\mathrm{NH}_{4}^{+}$at reduced $\mathrm{pH}$

Table 1

Overview of selected sites in the Netherlands Research Program on Particulate Matter and their characteristics of surrounding.

\begin{tabular}{ll}
\hline Site & Characteristics of surrounding \\
\hline Cabauw & $\begin{array}{l}\text { Rural site. Centre of the Netherlands, rural surrounding } \\
\text { (surrounded by urbanized areas in 20-40 km distance }\end{array}$ \\
Hellendoorn & $\begin{array}{l}\text { Rural site. East of the Netherlands, rural surrounding } \\
\text { Rural site. South of the Netherlands, rural surrounding, } \\
\text { intensive life stock breeding }\end{array}$ \\
Schiedam & $\begin{array}{l}\text { Urban background site. West of the Netherlands, Part of } \\
\text { Rotterdam agglomeration. Rotterdam has approximately } \\
600,000 \text { inhabitants close to refineries and harbour related }\end{array}$ \\
& $\begin{array}{l}\text { activities (Port of Rotterdam) } \\
\text { Kerbside location less than } 5 \text { m from the curbside and a } \\
\text { Rotterdam }\end{array}$ \\
&
\end{tabular}


Table 2

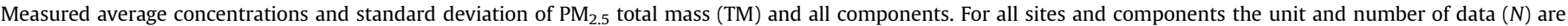
indicated.

\begin{tabular}{|c|c|c|c|c|c|c|c|c|c|c|c|}
\hline \multirow[t]{2}{*}{ Spec. } & \multirow[t]{2}{*}{ Unit } & $\mathrm{AVG} \pm \mathrm{STDEV}$ & \multirow[t]{2}{*}{$N$} & $\mathrm{AVG} \pm \mathrm{STDEV}$ & \multirow[t]{2}{*}{$N$} & $\mathrm{AVG} \pm \mathrm{STDEV}$ & \multirow[t]{2}{*}{$N$} & $\mathrm{AVG} \pm \mathrm{STDEV}$ & \multirow[t]{2}{*}{$\mathrm{N}$} & $\mathrm{AVG} \pm \mathrm{STDEV}$ & \multirow[t]{2}{*}{$N$} \\
\hline & & Schiedam & & Vredepeel & & Rotterdam & & Cabauw & & Hellendoorn & \\
\hline TM & $\mu \mathrm{g} \mathrm{m}^{-3}$ & $17.2 \pm 11.6$ & 76 & $17.5 \pm 9.2$ & 65 & $19.5 \pm 11.1$ & 85 & $18.5 \pm 12.3$ & 65 & $14 \pm 6.9$ & 65 \\
\hline $\mathrm{Al}$ & $\mathrm{ng} \mathrm{m^{-3 }}$ & $61.9 \pm 131.7$ & 82 & $35.4 \pm 54.6$ & 112 & $35.9 \pm 45.5$ & 113 & $32.3 \pm 32.5$ & 82 & $35.6 \pm 74.3$ & 82 \\
\hline As & $\mathrm{ng} \mathrm{m}^{-3}$ & $0.7 \pm 0.6$ & 82 & $0.7 \pm 0.5$ & 112 & $0.6 \pm 0.5$ & 113 & $0.5 \pm 0.5$ & 82 & $0.4 \pm 0.4$ & 82 \\
\hline $\mathrm{Ba}$ & $\mathrm{ng} \mathrm{m^{-3 }}$ & $11 \pm 56.3$ & 82 & $4.6 \pm 6$ & 112 & $10.5 \pm 45.3$ & 113 & $4.5 \pm 2.8$ & 82 & $5.5 \pm 16.5$ & 82 \\
\hline $\mathrm{Ca}$ & $\mathrm{ng} \mathrm{m} \mathrm{m}^{-3}$ & $87.5 \pm 76.8$ & 82 & $74.6 \pm 52$ & 112 & $82.8 \pm 61.3$ & 113 & $67.9 \pm 99.4$ & 82 & $61.7 \pm 55.8$ & 82 \\
\hline $\mathrm{Cd}$ & $\mathrm{ng} \mathrm{\textrm {m } ^ { - 3 }}$ & $0.3 \pm 0.3$ & 82 & $0.3 \pm 0.2$ & 112 & $0.3 \pm 0.2$ & 113 & $0.3 \pm 0.2$ & 82 & $0.3 \pm 0.2$ & 82 \\
\hline Co & $\mathrm{ng} \mathrm{m}^{-3}$ & $0.3 \pm 0.2$ & 82 & $0.2 \pm 0.1$ & 112 & $0.3 \pm 0.2$ & 113 & $0.2 \pm 0.1$ & 82 & $0.2 \pm 0.1$ & 82 \\
\hline $\mathrm{Cr}$ & $n g m^{-3}$ & $2.9 \pm 1.3$ & 82 & $3.1 \pm 1.6$ & 112 & $3.7 \pm 2.3$ & 113 & $2.8 \pm 2.1$ & 82 & $2.7 \pm 1.2$ & 82 \\
\hline $\mathrm{Cu}$ & $\mathrm{ng} \mathrm{m} \mathrm{m}^{-3}$ & $5.5 \pm 9.9$ & 82 & $3.5 \pm 2.3$ & 112 & $10.9 \pm 10.2$ & 113 & $3.3 \pm 3.6$ & 82 & $2.5 \pm 3.3$ & 82 \\
\hline $\mathrm{Fe}$ & $\mathrm{ng} \mathrm{m} \mathrm{m}^{-3}$ & $115.9 \pm 117.5$ & 82 & $86.9 \pm 75.7$ & 112 & $206.3 \pm 118.1$ & 113 & $82.1 \pm 75.3$ & 82 & $71.5 \pm 76.5$ & 82 \\
\hline K & $\mathrm{ng} \mathrm{m} \mathrm{m}^{-3}$ & $134.2 \pm 529.5$ & 82 & $112.7 \pm 102.3$ & 112 & $129.8 \pm 435.8$ & 113 & $84.4 \pm 77.9$ & 82 & $84 \pm 124.7$ & 82 \\
\hline $\mathrm{Mg}$ & $\mathrm{ng} \mathrm{m^{-3 }}$ & $64.9 \pm 86.9$ & 82 & $41.2 \pm 28.9$ & 112 & $50.5 \pm 69.7$ & 113 & $55.1 \pm 31.3$ & 82 & $44.6 \pm 33$ & 82 \\
\hline Mn & $\mathrm{ng} \mathrm{m}^{-3}$ & $4 \pm 3.4$ & 82 & $3.7 \pm 3.6$ & 112 & $5.3 \pm 3.8$ & 113 & $3.3 \pm 3.3$ & 82 & $2.6 \pm 2.3$ & 82 \\
\hline Mo & $\mathrm{ng} \mathrm{m}^{-3}$ & $0.6 \pm 0.4$ & 82 & $0.9 \pm 1.2$ & 112 & $1 \pm 0.7$ & 113 & $0.6 \pm 0.8$ & 82 & $0.5 \pm 0.4$ & 82 \\
\hline $\mathrm{Na}$ & $\mathrm{ng} \mathrm{m}^{-3}$ & $339.9 \pm 311.4$ & 82 & $206.4 \pm 209$ & 112 & $251 \pm 271.7$ & 113 & $259.3 \pm 239.7$ & 82 & $173.8 \pm 201$ & 82 \\
\hline $\mathrm{Ni}$ & $n g m^{-3}$ & $5.4 \pm 4$ & 82 & $2.1 \pm 1.3$ & 112 & $4.4 \pm 3.6$ & 113 & $2.7 \pm 1.7$ & 82 & $1.9 \pm 1.2$ & 82 \\
\hline $\mathrm{P}$ & $\mathrm{ng} \mathrm{m}^{-3}$ & $90 \pm 37.7$ & 82 & $78.3 \pm 39$ & 112 & $87.1 \pm 36.9$ & 113 & $78 \pm 37$ & 82 & $80.1 \pm 36.3$ & 82 \\
\hline $\mathrm{Pb}$ & $\mathrm{ng} \mathrm{m}^{-3}$ & $9.1 \pm 11.9$ & 82 & $10 \pm 9.2$ & 112 & $8.9 \pm 12$ & 113 & $11 \pm 14.8$ & 80 & $8.3 \pm 12.5$ & 80 \\
\hline $\mathrm{Sb}$ & $n g m^{-3}$ & $1 \pm 1$ & 82 & $0.7 \pm 0.5$ & 112 & $1.6 \pm 0.9$ & 113 & $0.8 \pm 0.8$ & 82 & $0.6 \pm 0.5$ & 82 \\
\hline Se & $\mathrm{ng} \mathrm{m^{-3 }}$ & $2.7 \pm 5.8$ & 82 & $1.3 \pm 0.9$ & 112 & $1.9 \pm 2.4$ & 113 & $1 \pm 0.8$ & 82 & $0.8 \pm 0.6$ & 82 \\
\hline $\mathrm{Si}$ & $\mathrm{ng} \mathrm{m}^{-3}$ & $93.2 \pm 171.3$ & 82 & $79.9 \pm 102.9$ & 112 & $76.3 \pm 43.7$ & 113 & $73.5 \pm 64.1$ & 82 & $84.5 \pm 143.8$ & 82 \\
\hline Sn & $\mathrm{ng} \mathrm{m}^{-3}$ & $4.2 \pm 11.2$ & 82 & $1.4 \pm 1$ & 112 & $3 \pm 2.1$ & 113 & $1.3 \pm 1.7$ & 82 & $0.9 \pm 0.8$ & 82 \\
\hline $\mathrm{Sr}$ & $n g m^{-3}$ & $2.2 \pm 12.4$ & 82 & $0.8 \pm 1.2$ & 112 & $1.6 \pm 9.4$ & 113 & $0.8 \pm 0.6$ & 82 & $0.9 \pm 2.2$ & 82 \\
\hline $\mathrm{Ti}$ & $\mathrm{ng} \mathrm{m^{-3 }}$ & $2.5 \pm 2.9$ & 82 & $1.7 \pm 1.9$ & 112 & $1.9 \pm 1.1$ & 113 & $1.5 \pm 1.1$ & 82 & $1.5 \pm 2$ & 82 \\
\hline V & $\mathrm{ng} \mathrm{m}^{-3}$ & $9 \pm 7.7$ & 82 & $2.4 \pm 2.1$ & 112 & $6.5 \pm 6.9$ & 113 & $3.7 \pm 3.3$ & 82 & $2 \pm 1.9$ & 82 \\
\hline Zn & $\mathrm{ng} \mathrm{m}^{-3}$ & $95.3 \pm 36.7$ & 82 & $92 \pm 40$ & 112 & $94.6 \pm 35.4$ & 113 & $99.5 \pm 39.2$ & 82 & $90.5 \pm 31.7$ & 82 \\
\hline OC & $\mu \mathrm{g} \mathrm{m}^{-3}$ & $2.1 \pm 1.1$ & 46 & $2 \pm 1$ & 87 & $2.3 \pm 1.1$ & 79 & $1.8 \pm 0.6$ & 34 & $2 \pm 0.8$ & 61 \\
\hline EC & $\mu \mathrm{g} \mathrm{m}^{-3}$ & $2.2 \pm 1.6$ & 46 & $1.9 \pm 1.3$ & 87 & $3.4 \pm 1.8$ & 79 & $1.6 \pm 0.9$ & 34 & $1.7 \pm 1.1$ & 61 \\
\hline $\mathrm{NH}_{4}^{+}$ & $\mu \mathrm{g} \mathrm{m}^{-3}$ & $1.2 \pm 1.5$ & 46 & $1.9 \pm 1.5$ & 85 & $1.6 \pm 1.9$ & 79 & $1.4 \pm 1.3$ & 34 & $1.6 \pm 1.4$ & 61 \\
\hline $\mathrm{NO}_{3}^{-}$ & $\mu \mathrm{g} \mathrm{m}^{-3}$ & $2.8 \pm 3.4$ & 46 & $4.2 \pm 2.9$ & 86 & $3.5 \pm 3.7$ & 79 & $3.6 \pm 3.4$ & 34 & $3.7 \pm 3.1$ & 61 \\
\hline $\mathrm{SO}_{4}{ }^{2-}$ & $\mu \mathrm{g} \mathrm{m}^{-3}$ & $2.6 \pm 1.4$ & 46 & $2.9 \pm 2.2$ & 86 & $2.6 \pm 2.1$ & 79 & $2.4 \pm 1.4$ & 34 & $2.6 \pm 1.8$ & 61 \\
\hline $\mathrm{Cl}$ & $\mu \mathrm{g} \mathrm{m}^{-3}$ & $0.3 \pm 0.3$ & 46 & $0.4 \pm 0.4$ & 86 & $0.4 \pm 0.5$ & 79 & $20.3 \pm 20.3$ & 34 & $0.3 \pm 0.3$ & 61 \\
\hline
\end{tabular}

by conductivity. Detection levels for sulphate/nitrate and ammonium are 0.7 and $0.2 \mu \mathrm{g}$ per quartz filter, respectively.

The analysis on the presence of carbon on the quartz filters is based on thermography ("Cachier-method"). This means that a filter-sample is heated in an oven resulting in the release of carbon (Brink et al., 2009). For quantitative determination of the amount of released carbon the evolved gases are oxidized to $\mathrm{CO}_{2}$ in a post-combustor oven. It is noted that the discrimination of carbon in $O C$ and EC is operationally defined. $O C$ is equal to the carbon released in the 1 st step $\left(8 \mathrm{~min}\right.$ at $\left.340{ }^{\circ} \mathrm{C}\right)$; the remainder gives an estimate for EC after combustion for $6 \mathrm{~min}$ at $750{ }^{\circ} \mathrm{C}$. The analysis occurs in a Coulomat 702, manufactured by JUWE (Viersen, Germany). Several samples were in the oven for a longer time and also at a higher temperature to check for complete combustion and proper assessment of EC. The minimum detection limit of the method is around $5 \mu \mathrm{g}$ per filter.

The standard operational procedure in the NAQMN using Inductively Coupled Plasma Mass Spectrometry (ICP-MS) was employed to analyze the elemental composition of the collected $\mathrm{PM}_{2.5}$. In short, ICP-MS is capable of determining a range of metal and non-metal concentrations with high sensitivity. Although the measuring of these elements is relatively straight forward, the quantitative extraction of all elements is a challenge. In this study the Teflon filters were microwave digested with a nitric acid $/ \mathrm{H}_{2} \mathrm{O}_{2}$ solution, known to be associated with a partial recovery of some crustal materials. These were corrected following Schaap et al. (2010). Nonetheless, a somewhat higher uncertainty is associated with these analyses.

\subsection{Mass closure}

The chemical analysis of the particulate mass performed in this study covers a characterization of a major part of the total mass concentration. Nonetheless, a significant part of the mass is not analyzed. These include non-measured oxides, the contribution of the non carbon atoms $(\mathrm{H}, \mathrm{O}, \mathrm{N}$, etc) in organic material and subsequent water. A full mass closure analysis of this dataset is presented by Schaap et al. (2010) and Weijers et al. (2011) including the assumptions to obtain the best estimates for the missing oxides and non-carbonaceous organic material. After summing up the individual species with these corrections applied still 10-15\% of the total measured $\mathrm{PM}_{2.5}$ mass appears unexplained. An overview of the average concentrations and the standard deviation for the analyzed species as well as the number of samples for each location are given in Table 2 . In this paper we will use the multivariate factors from the PMF analyses to determine which of the factors correlate with the (un)explained mass.

\subsection{Source apportionment}

Receptor-oriented or receptor models can be used to identify sources and the apportionment of the observed pollutant concentrations to those sources (Hopke, 1991). These models search for correlation between the different (groups of) components in time and use these to find an optimal solution to explain all observed concentrations by decomposing a matrix of speciated sample data. The data are interpreted on a pure statistical basis without preformulated assumptions providing an independent source of information. To decompose the speciated sample matrix we use a multivariate factor analysis tool called Positive Matrix Factorization (PMF) (Paatero and Tapper, 1994). We have performed all calculations in robust mode with EPA-PMF 3.0, a program which uses ME-2 as the underlying engine to solve the PMF problem (Paatero, 1999; Norris et al., 2008). For detailed descriptions and the underlying equations for both the PMF technique and the ME-2 engine we refer to 
Paatero (1999), Ramadan et al. (2003), Kim et al. (2005), Kim and Hopke (2005, 2008) and Norris et al. (2008). Rotational ambiguity is one of the major challenges for the physical interpretation of the solution. Using a non-negativity constraint is the first step to limit this ambiguity but this alone does not produce a unique solution by default (Paatero et al., 2002). Note, the non-negativity assumption has a small impact on the results concerning profiles that are subject to transformation processes such as chloride displacement in sea salt. These profiles might be "average" profiles or they will resolve in separate profiles before and after the change, provided these "sources" have sufficient variability in time and space (Brown and Hafner, 2005). The parameter FPEAK has been used to control the rotations and the solution with the lowest sum-of-squares ( $Q$ value) has been retained, as suggested by Juntto and Paatero (1994).

We assumed that the variation between the composition of the contribution of the same type of source between sites is relatively small. For example, the contribution of the traffic factor has to be predominately higher at a traffic site compared to a rural site, but the composition of the source is the same at both sites. Under this assumption, we have combined the datasets of all sites. This also ensures that the number of observations is such that the statistical procedure produces more robust results. By combining the dataset the analysis will provide insight in sources affecting all five receptor sites, and will most likely tend to focus on the general phenomena instead of the unique local variations (Escrig Vidal et al., 2009).

Application of PMF requires a dataset in which all components have a valid concentration value. As most of the different tracers are supplied by the ICP-MS, only sampling days with a complete set of ICP-MS analysis have been used. The quality of the results of the analysis is ensured by a sequence of $\mathrm{QA} / \mathrm{QC}$ procedures. For some results this sequence of prove of quality is incomplete however the data itself are likely to be useful. After a plausibility test these data are used in the PMF analysis with a lower weight. Data below the minimum detection limit (MDL) were replaced by half the MDL and the corresponding uncertainty was set to $5 / 6$ times the MDL (Polissar et al., 1998; Kim et al., 2003a; Kim and Hopke, 2004b; Nicolás et al., 2008). The uncertainty is set relatively high to lower the impact on the final result and to avoid inducing strong false correlations. Still, after these procedures approximately $6 \%$ of the samples contained missing data for either ions or EC/OC. Multiple imputation (MI: Rubin, 1976, 1977; Hopke et al., 2001) was used to estimate missing values. The MI technique provides estimates for the missing values based on the statistical relations between the data and has been frequently applied in the fields of environmental research and biostatistics (Baccarelli et al., 2005; Ibrahim et al., 2005; Yang et al., 2005). Imputated samples had their corresponding uncertainty multiplied by a factor 4 prior to use in the PMF analysis.

Not every chemical species may provide valuable information to solve the PMF problem (Paatero and Hopke, 2003). It was suggested using the signal-to-noise ratio $(\mathrm{S} / \mathrm{N})$ as an indicator for qualifying species. Paatero and Hopke (2003) suggest retaining components with a signal-to-noise ratio of 2.0. Here, we use only components with a signal-to-noise ratio greater than 1.5 to facilitate the inclusion of specific tracer species. To take into account the errors which are not considered measurements or lab errors all runs were performed with an added "Extra Modelling Uncertainty" of 5\% applied to all species (Norris et al., 2008).

We have included the total $\mathrm{PM}_{2.5}$ mass from the weighed filters as an independent variable to obtain the mass apportionment (Kim et al., 2003a). This procedure also provides an indirect means to verify to a certain extent that the PMF worked properly by comparing the apportioned mass to the sum of the components. To limit the influence on the final solution the uncertainties of the $\mathrm{PM}_{2.5}$ mass have been multiplied by a factor three (Norris et al., 2008).
When applying the PMF technique one has to select the number of factors that will provide the best description of the dataset. This selection is always a compromise: too few factors will likely combine sources in one source profile, whereas too many factors will dissociate a real factor into additional but non-existing sources. We used the theoretical $Q$ value (Paatero et al., 2002), scaled residuals for each species, the evaluation of the scaled residual matrix (Lee et al., 1999) and the physical meaning of each factor to evaluate different factor solutions.

The spatial variability or the degree of uniformity of the calculated source contributions at the selected sites was determined using the coefficients of divergence (COD) (Kim et al., 2005; Kim and Hopke, 2005, 2008). The COD is a coefficient used to determine the resemblance between objects or the variables describing these objects. For the spatial distribution the COD approaches zero if the source contributions at the compared sites are highly correlated. In case the source contributions are very different the COD approaches unity. We have excluded (small) negative daily source contributions from the calculation.

Kim and Hopke (2004a) demonstrated the usefulness of a technique using the Conditional Probability Function (CPF) in which sources are likely to be located in the directions that have high conditional probability values (Hwang and Hopke, 2006; Xie and Berkowitz, 2006). We have combined the calculated source contributions with the hourly wind data from nearby meteorological stations (data courtesy of the Royal Netherlands Meteorological Institute (KNMI)). To match the hourly wind data and to minimize the averaging effect of diurnal wind changes each daily contribution was assigned to each hour of a given day (Kim et al., 2003a,b; Kim and Hopke, 2008). The CPF is defined as:

$\mathrm{CPF}=\frac{m_{\Delta \theta}}{n_{\Delta \theta}}$

where $m_{\Delta \theta}$ is the number of occurrence from wind sector $\Delta \theta$ that exceed the threshold criterion, and $n_{\Delta \theta}$ is the total number of data from the same wind sector. In this study $\Delta \theta$ was set at $30^{\circ}$, and calm winds $\left(<1 \mathrm{~m} \mathrm{~s}^{-1}\right)$ were excluded. The threshold was set at the upper 25th percentile of the contribution from each source.

\section{Results and preliminary discussion}

\subsection{Summary of $P M_{2.5}$ mass and composition}

The average $\mathrm{PM}_{2.5}$ concentrations at the 5 receptor sites range between 12.5 and $17.5 \mu \mathrm{g} \mathrm{m}^{-3}$. The highest levels were observed at Rotterdam ('traffic') while the lowest occur at Hellendoorn ('rural') as expected. In general, considerable similarity exists in the chemistry of $\mathrm{PM}_{2.5}$ at the various sites. The largest mass contributions come from nitrate and also the importance of elementary carbon at the curbside is remarkable (caused by the nearby vehicular emissions). The next important component (in absolute value) is sulphate, which is followed by organic and elemental carbon (Weijers et al., 2011).

Further clustering of components reveals that the components related to secondary inorganic aerosol (SIA) are the most dominant (Weijers et al., 2011). The SIA concentrations are higher at the rural sites (46-48\%) whereas (slightly) lower percentages are found at the urban stations. The second dominant contribution to $\mathrm{PM}_{2.5}$ comes from total carbon matter (TCM): it ranges between 26 and $41 \%$ with a maximum at the traffic site Rotterdam. The contribution of the remaining components like sea salt (3-8\%), crustal material (3-5\%) and metals (3-5\%) is relatively small in $\mathrm{PM}_{2.5}$ and rather independent of measurement site. The mass closure procedure is able to explain near $100 \%$ of the mass at the urban locations 
Schiedam ( $<1 \%$ ) and Rotterdam (3\%), and at rural Hellendoorn (5\%), whereas larger unexplained parts in $\mathrm{PM}_{2.5}$ exist at rural Vredepeel (13\%) and Cabauw (16\%) (Weijers et al., 2011). The composition of $\mathrm{PM}_{2.5}$ mass has been reported in more detail by Weijers et al. (2011).

\subsection{Source apportionment using PMF}

To estimate the number of source factors the behaviour of the PMF solution was studied for a range of 3-14 factors. Although the selection of the number of factors is somewhat arbitrary the evaluation showed that a seven factor solution yielded the most tangible comprehensible results. To ensure convergence of the PMF problem 250 additional runs for the 7-factor solution using random starting seeds were performed. Additionally we found that an FPEAK value of zero produced the lowest $Q$ value, with a $Q$ (robust) of 11,509 compared to a theoretical $Q$ of approximately 11,751 . The results of the PMF are given in Fig. 2. The factors (1-7) are given in order of decreasing total $\mathrm{PM}_{2.5}$ mass contribution provided by the inclusion of total $\mathrm{PM}_{2.5}$ mass in the PMF analysis. As an evaluation of the results we have compared the predicted total mass, i.e. the summed contributions of each source, to the measured mass for each day. Linear regression shows a good correlation between
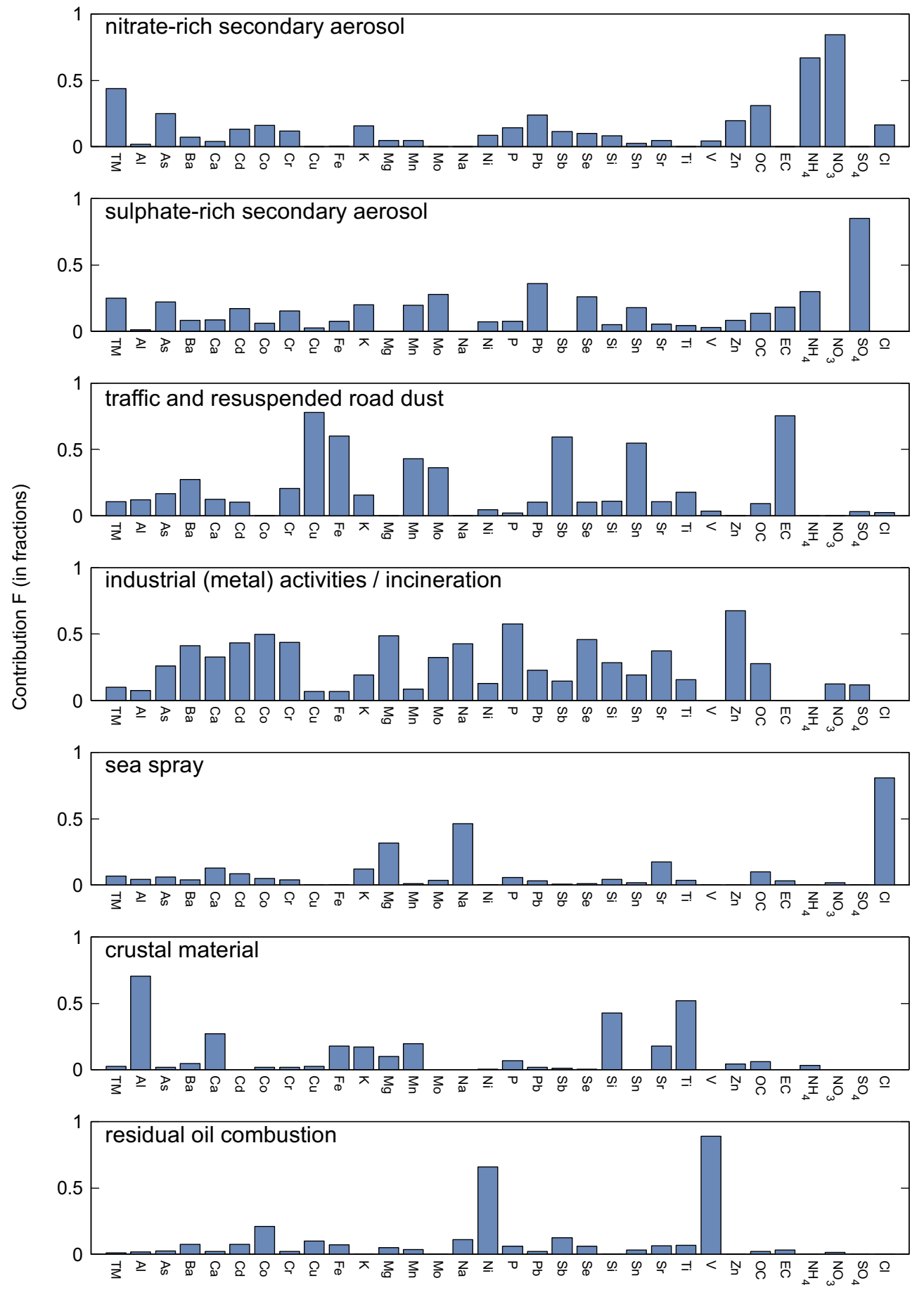

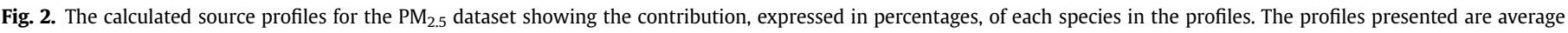
profiles for the used receptor sites. 
predicted versus measured mass with a correlation coefficient of 0.8016 , proving confidence in the results. Below we discuss the factor identification.

\subsubsection{Factor identification}

Factor 1 consists mainly of the secondary aerosol components nitrate and ammonium and is thought to be mostly the semivolatile ammonium nitrate. A seasonal pattern in the mass concentration in this factor is expected and observed as temperature greatly affects the equilibrium of ammonium nitrate, ammonia, and nitric acid. Low temperature during winter favours the formation of the particulate form. The concentration of ammonia in the Dutch atmosphere is such that when sulphate is fully neutralized a considerable amount is left to stabilize the ammonium nitrate also in summer. The origin of nitrate is the oxidation of $\mathrm{NO}_{2}$ emitted by combustion processes, mainly traffic. Although sources that emit nitrogen oxides generally also emit carbonaceous material they are not so much coupled as the primary carbonaceous and secondary nitrate are expected to behave quite differently. Only a limited contribution of OC is associated with this profile. This is not unrealistic as part of the $O C$ is also thought to be semi-volatile (Donahue et al., 2009). Factor 1 is categorized as 'nitrate-rich secondary aerosol'.

Factor 2 contains mainly secondary sulphate. Furthermore, this factor contains a fraction of $\mathrm{OC}$ and EC. The origin of the sulphate is the atmospheric oxidation of $\mathrm{SO}_{2}$ and it is associated with longrange transport. The $\mathrm{SO}_{2}$ derives from the combustion of sulphur containing fuels. As expected the seasonal variation of factor 2 resembles the long-term average of sulphate (Weijers et al., 2011). Factor 2 is categorized as 'sulphate-rich secondary aerosol'.

Factor 3 consists mainly of elemental carbon (EC), a small amount of organic carbon (OC), and is associated with a range of metals (e.g. Fe, $\mathrm{Cu}, \mathrm{Ba}, \mathrm{Mn}, \mathrm{Mb}, \mathrm{Sb}, \mathrm{Sn}$ ). The large contribution of EC a component released by combustion, along with these metals suggests that factor 3 can be labelled as traffic emissions. In this case the EC represents the tail pipe emissions. Metals such as iron are associated with mechanical wear (Hildemann et al., 1991). Several studies have linked high concentrations of copper to brake wear (Sternbeck et al., 2002; Laschober et al., 2004; Denier van der Gon et al., 2007), whereas barium (Ba) emissions are linked to tyre wear (Fernández-Espinosa and Ternero-Rodríguez, 2004). Molybdenum $(\mathrm{Mb})$ is used as an additive in lubricants and is also released in the environment from the combustion of fossil fuels, explaining the contribution of molybdenum in this factor (Salminen et al., 2005). Thus, factor 3 is categorized as 'traffic'. Specific weekday/ weekend variations are observed, as expected with a traffic source. Note that the enrichment of this factor with crustal elements is very limited; suggesting that dust resuspension by traffic is not a major source. This may be due to the fact that resuspension yields primarily coarse mode particles (Thorpe et al., 2007), whereas the wear processes yield considerable contributions to the fine mode (Denier van der Gon et al., 2007). Also, only one street location at a busy intersection is used here, which may not be representative for general conditions. In short, the low contribution of crustal matter at the street site needs to be verified in the future. The CPF plot for the traffic related source show contributions are from the north-east of the receptor site (Fig. 3). This corresponds with the location of the traffic junction nearby the measurement site.

Factor 4 contains large fractions of a host of metals, which could not be identified as a single source. High concentrations of zinc, lead, nickel, cobalt and arsenic are mainly contributed by industrial activities such coal and waste combustion (Marcazzan et al., 2001; Salminen et al., 2005; Pacyna and Pacyna, 2001). Chromium, zinc, cobalt, strontium and to some extend nickel are also associated with steel processing and other metallic industrial activities
(Salminen et al., 2005; Song et al., 2001; Lee et al., 1999). The main sources for calcium are cement factories, dust and fertilizers. Phosphorous, potassium, magnesium and cobalt in this factor may also be associated with fertilizers (Salminen et al., 2005). Based upon the elemental composition of this source it seems to be a mixture of many different sources, not limited to waste incineration, (coal) combustion, metallic industrial activities and fertilizers. We summarize the profile as industrial activities and incineration. Besides Rotterdam and Schiedam none of the measurement sites were located nearby major industrial activities.

Factor 5 shows enhanced fractions of sodium, magnesium, chloride and to a lesser extent potassium. These tracers are mainly associated with the sea salt particles. The origin of the factor is clearly located to the west of the Netherlands, as can be seen in Fig. 3 for the CPF plot of the sea spray factor at Cabauw. Hence, labelling this factor was straight forward and factor 5 is categorized as 'sea spray'. Note that sea salt also contains some sulphate. However, no sulphate is appointed to this factor. We expect that it is difficult for a statistical method based on correlations to differentiate a small fraction of total sulphate to be associated with sea salt when sea salt and sulphate show a distinct anti-correlation in time.

Factor 6 contains the typical elements of crustal material (CRM). These are particularly silicon, aluminium, and titanium but also calcium and iron. The concentrations of silicon, aluminium and titanium show an excellent correlation with each other (see also Denier van der Gon et al., 2010). The factor also includes some organic carbon $(\mathrm{OC})$, as is reported by many authors (Lewis et al., 2003; Lee et al., 2006) and points to detritus from vegetation and other organic soil constituents.

Factor 7 contains significant fractions of the measured vanadium and nickel concentrations. Together with EC and OC these are the tracers for crude oil combustion (Olmez et al., 1988) and incineration. Typical oil combustion sources are shipping, municipal district heating power plants and industrial power plants using heavy oil. A recent study by Vallius (2005) showed inland shipping can also be considered a source of particulate matter. Factor 7 is categorized as 'residual oil combustion'. At Schiedam the highest contributions for the residual oil combustion are coming from west from the site, but a dominant source might be located in the northwestern direction (Fig. 3). The CPF plot for Schiedam points to the harbour of Rotterdam, which contains several oil refineries, as well as shipping activities.

\subsubsection{Spatial distribution of the calculated sources}

The attributed contribution of each factor to the total $\mathrm{PM}_{2.5}$ mass, which was included in the analysis as an independent variable, is shown for all stations in Fig. 4. In general the contributions of all factors show a consistent picture over all sites. The largest part of the $\mathrm{PM}_{2.5}$ mass is explained by nitrate and sulphate-rich secondary aerosol. Together these two factors explain on average $69 \%$ of the apportioned $\mathrm{PM}_{2.5}$ mass. The nitrate-rich factor dominates with on average $44 \%$ compared to $25 \%$ for the sulphate-rich factor. The highest contribution is found at the rural sites, located away from the coast. The lowest contribution is found at the traffic station in Rotterdam, explained by the presence of local sources. Not surprisingly, this local source is caused by the factor attributed to be traffic related emissions. At Rotterdam these contribute about $21 \%$ of the fine particulate mass, whereas at the rural sites a contribution of $5-7 \%$ is found. Industrial metal activities and incineration contribute about $10 \%$ at all sites. This would suggest, although industrial activities are considered to be mostly local point sources, the found profile is behaving like an area source with similar contributions on all five sites. Sea salt shows a rather flat relative contribution as well, though the absolute concentrations in Rotterdam and Schiedam, both located nearby the coastline of the 


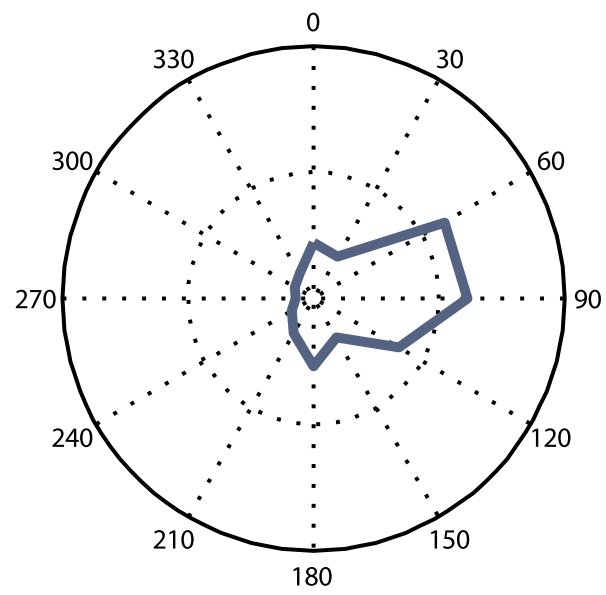

nitrate-rich secondary aerosol

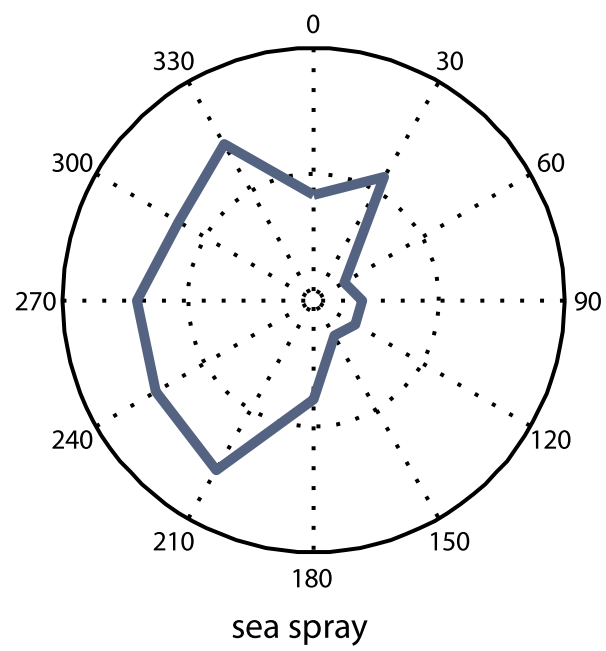

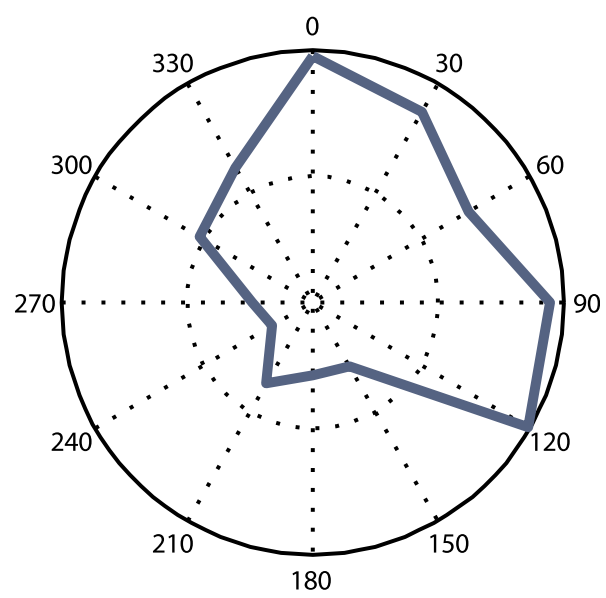

traffic and resuspended road dust

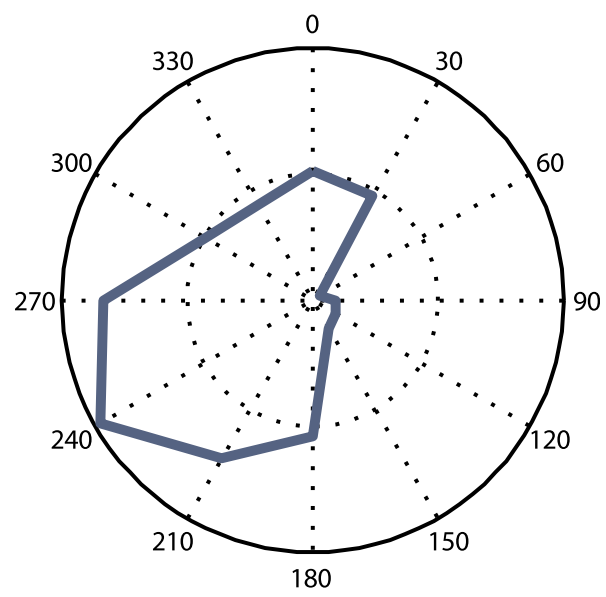

residual oil combustion

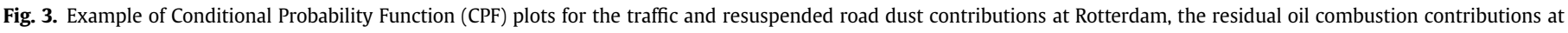
Schiedam and the sea spray contribution at Cabauw.

North Sea, are higher than on the rural sites, which are located further away from the coast. The final contribution from residual oil combustion is low at all sites, though a maximum at the urban background site in Schiedam can be observed. Schiedam is located near the Port of Rotterdam, known for its industrialized surroundings and shipping harbour.

The spatial variability of the calculated source contributions are addressed using the coefficients of divergence (COD), see Fig. 5. All combinations of sites yield almost the same low COD for sulphaterich secondary aerosol. This behaviour has also been found by several previous studies for sulphate dominated profiles (Kim et al., 2005; Kim and Hopke, 2008). The importance of long-range transport into and across the monitored area is reflected in the small spatial variability. The factor nitrate-rich secondary aerosol also shows a relatively small spatial variability on average. However, the COD for nitrate tends to increase as function of distance. Hence, the highest COD value was found between Hellendoorn and Schiedam (0.56). The larger range in COD values indicates a larger gradient and a smaller correlation distance within the Netherlands than that of the sulphate-rich factor. This may be explained by the nature of ammonium nitrate, a semi-volatile component, and therefore more variable depending on ambient conditions and precursor gas concentrations (Ansari and Pandis, 1998).

As expected, a significant larger spatial variability is found for the traffic factor with the largest CODs between the urban/street sites and the rural sites. Interestingly, the low COD values between the rural sites indicate that the source contribution on these sites behaves similarly. This may indicate a traffic related background across the Netherlands originating from distant sources. However, we expect that the origin is not from a distant source but rather due to the diffuse but highly correlated nature of traffic emissions in time. This has been suggested earlier by Schaap and Denier van der Gon (2007), who found a very strong correlation between measured Black Smoke concentrations at rural background stations between different regions in the Netherlands. These authors proved that most of the regional EC concentrations were due to national traffic emissions by using a model. As for the regional traffic contributions the industrial (metal) activities/incineration profile has a small spatial variability. Because none of the sites, besides the sites in the Rotterdam area, reflects an industrial area, where these sources may be located, all stations with respect to this source may be regarded as background. This is elaborated by the fact we didn't find the highest contribution of this source on either Rotterdam or 


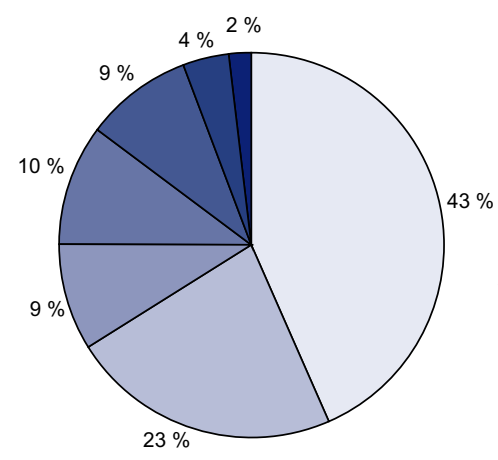

Schiedam

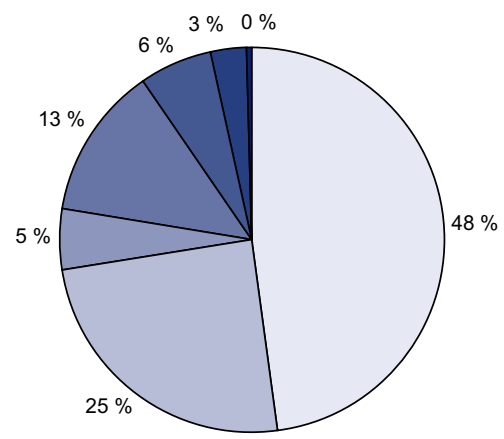

Hellendoorn

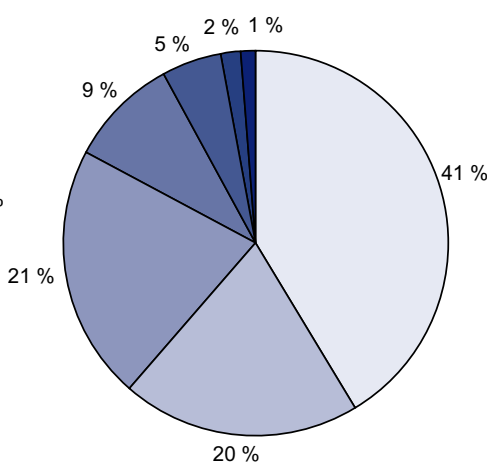

Rotterdam

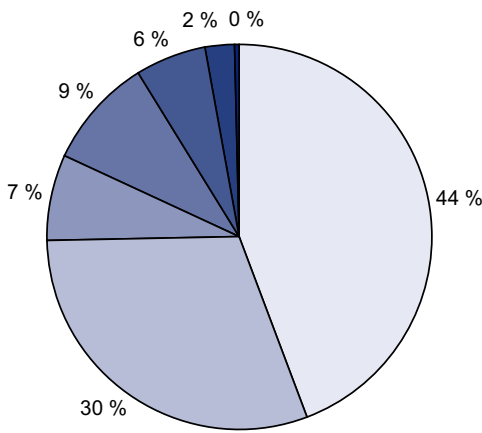

Vredepeel

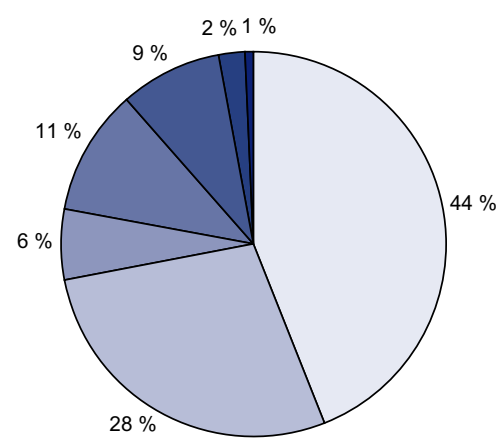

Cabauw

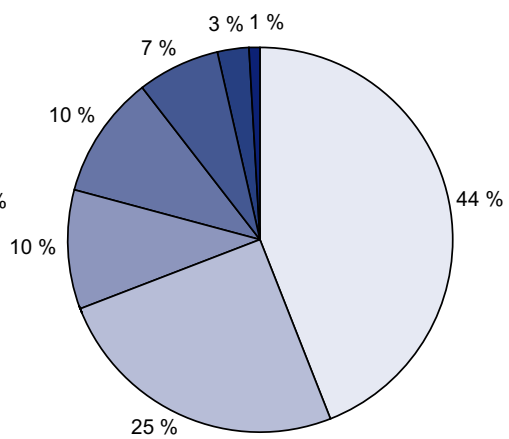

Average source contributions for all sample sites

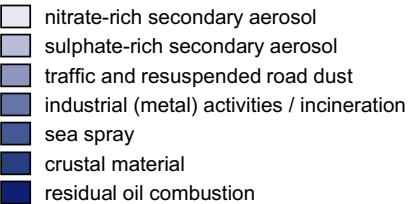

Fig. 4. Source contributions expressed in percentages of apportioned $\mathrm{PM}_{2.5}$ mass for the 5 monitoring sites in the Netherlands and the average contributions over these sites.

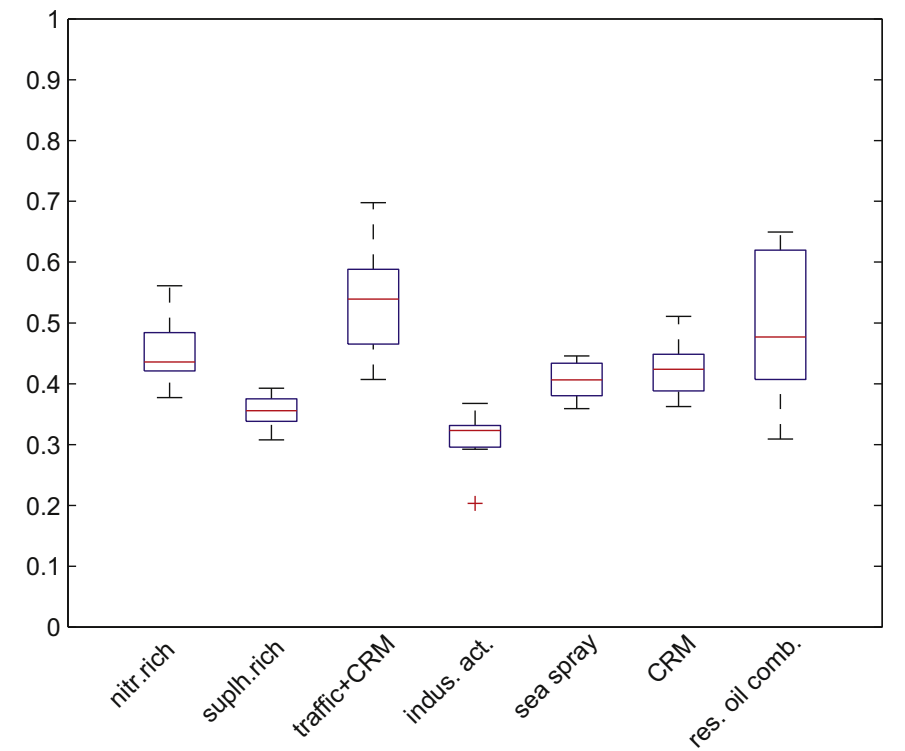

Fig. 5. Coefficients of divergence (COD) for identified $\mathrm{PM}_{2.5}$ sources obtained at the 5 monitoring sites in the Netherlands.
Schiedam, the only sites in with industrial activities in the vicinity. In addition, the profile probably reflects a host of different, diffuse sources, which may explain the low spatial variability.

The factor sea salt also shows a small spatial variability. This was expected as all stations are relatively close to the coast $(<100 \mathrm{~km})$, and sea spray aerosols peak at all sites during transport from the sea (Manders et al., 2009). The COD values for crustal material are very similar to those of sea spray. This result is surprising as the sources for mineral dust are many compared to one distinct source for sea salt. It was postulated that a peak concentration at the same day at all sites during a three day period 23-25 January 2008 of enhanced CRM concentrations may have dominated the COD value. However, removing the episode days from the analysis did not impact the COD value, falsifying this hypothesis. Back-trajectory analysis using HYSPLIT (Draxler and Hess, 1998) identified the event as a Saharan Dust episode (Fig. 6). Elevated PM concentration during this period was also observed by the London Air Quality Network (2008).

Finally, the second largest spatial variability is found for the residual oil combustion source. The COD between Schiedam and Rotterdam is the lowest at 0.31 , whereas the COD between the sites in the Rotterdam area and the rural sites is almost a factor 2 higher. The higher source contributions as well as the low COD within the Rotterdam area indicate that the source is located in or close to the Rotterdam area. Considering the nearby harbour activities, intensive shipping and petrochemical industries located in the Port of Rotterdam this is quite plausible. 


\section{NOAA HYSPLIT MODEL \\ Backward trajectories ending at 0000 UTC 24 Jan 08 GDAS Meteorological Data}

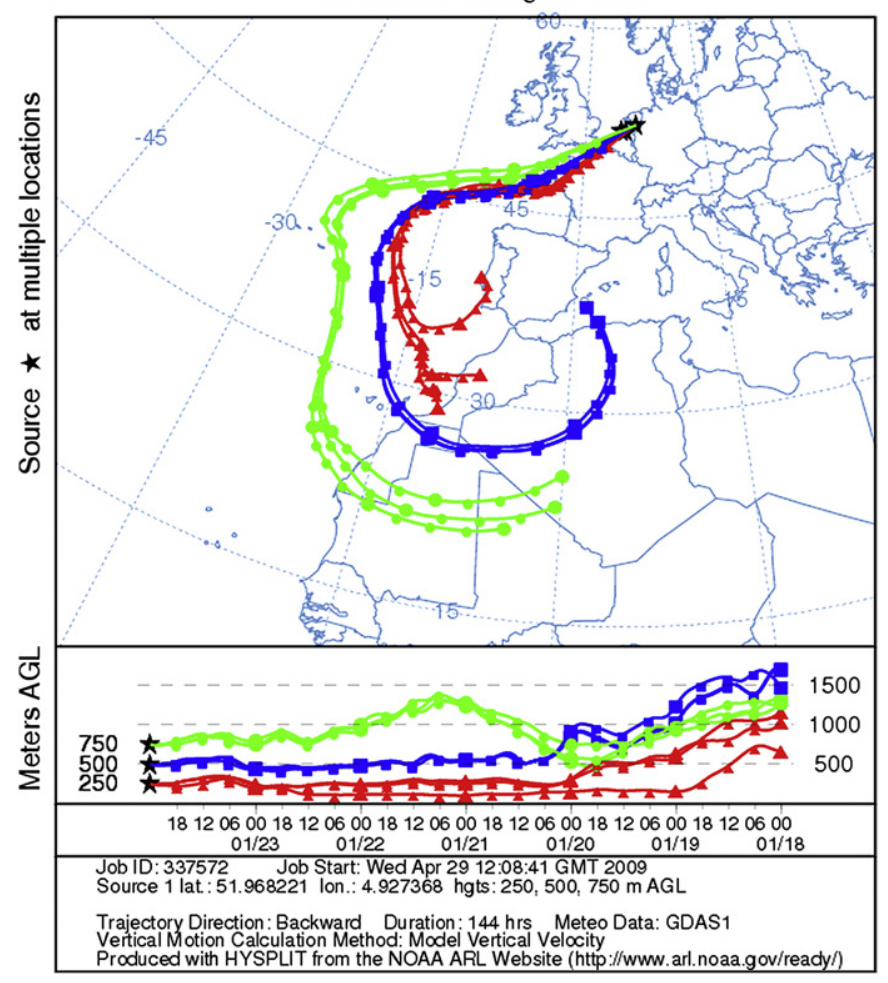

Fig. 6. HYSPLIT analysis with backward trajectories ending at 0000 UTC 24 January 2008, using heights of 250, 500 and $750 \mathrm{~m}$ above ground level (AGL).

\subsubsection{Temporal variations of the source profiles}

We have examined the seasonal variations of the source profiles using the ratio between the seasonal median contributions and the yearly median contribution for each source from the PMF analysis as shown in Fig. 7. The nitrate-rich secondary aerosol profile clearly shows a higher contribution to the total PM mass in the winter opposed to the contribution in the summer. This seasonal pattern in the mass concentration in this factor was expected, as temperature strongly affects the equilibrium of ammonium nitrate, ammonia and nitric acid. The flat seasonal pattern of the sulphate-rich secondary aerosol profile resembles the long-term average of sulphate (Weijers et al., 2011). The traffic and resuspended road dust profile show a typical seasonal pattern for primary pollutants with low contributions to the total PM mass during the summer period and the highest contribution during the fall. These seasonal differences are driven by the seasonal variation in dilution, most notably mixing layer depth. Furthermore, a clear weekday/ weekend pattern was found for this profile, with much higher contributions during weekdays compared to the weekend. Similar traffic induced day of the week variability has been found in many other studies (e.g. Schaap and Denier van der Gon, 2007).

The contribution on total PM mass for the sea spray profile is the highest in the winter period. This period was a windy season with large low pressure systems over the Atlantic Ocean and the North Sea (Manders et al., 2009). The Saharan dust episodes during the spring of 2008 contribute to the high contribution to the total PM mass of the crustal material factor during this season. However, high contributions during both the spring and the summer period are also expected for this profile due to agriculture activities, especially around Cabauw, Vredepeel and Hellendoorn, and dryer ambient and surface conditions.

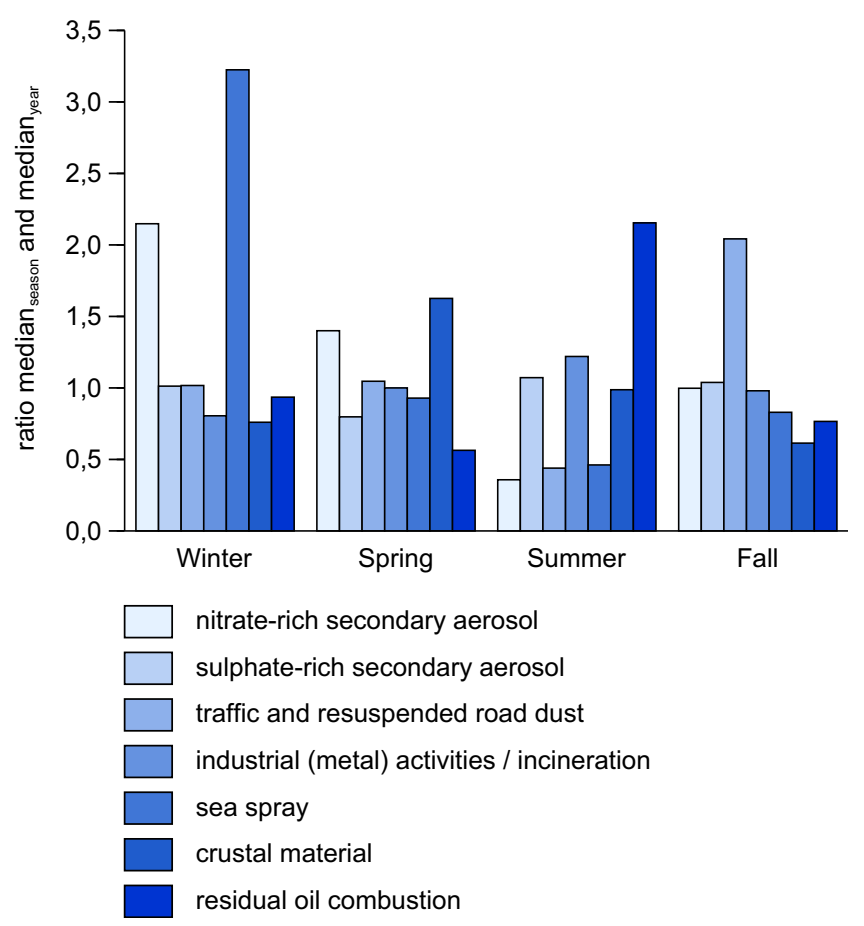

Fig. 7. Seasonal variations for the 7 average profiles for the used receptor sites, as expressed as median season $_{\text {median }}$ year for each source.

The industrial (metal) activities/incineration profile has a more or less constant seasonal pattern. However, it seems the contribution on the total PM mass during the summer is slightly higher compared to the other seasons. Due to the lack of both a seasonal pattern and the similar contribution on all receptor sites we assume this profile can be considered mainly as a common source containing negligible local contributions.

The residual oil combustion profile clearly shows a high contribution during the summer season. We have established that this source seems to be primarily a local source with high contributions in the Rotterdam area. Guo et al. (2009) observed the same seasonal pattern for a similar source in Hong Kong and concluded that it was related to marine vessel activities around the Hong Kong port. Based on the seasonal variation found in this study some of the contributions of this source are likely to be related to the marine vessel activities around the Port of Rotterdam. The Port of Rotterdam is also well known for its petrochemical industry, another contributor to the residual oil combustion source. Due to the use of high flue gas stacks a similar seasonal pattern, as observed in this study, can be found for these types of sources. During the winter period the flue gases will be exhausted above the atmospheric mixed-layer height which leads to lower contributions of this source on the ground level. The opposite is observed during the summer period when the atmospheric mixed-layer height exceeds the stack height. The residual oil combustion profile is likely a combination of emissions from shipping and petrochemical industry.

\subsubsection{Mass closure for each factor}

The PMF generates time and composition profiles. Regression of the time profiles with the real weighted $\mathrm{PM}_{2.5}$ mass shows the relative importance of each profile. Comparing this regression result to the summation of the component contributions in the profile, shows which profiles are associated with missing mass (shown in Table 3). In the summation of the components the metals were expressed as their oxides following Weijers et al. (2011). Comparing these results show that the nitrate/sulphate and sea 
spray fact all have a relatively low ratio of 0.7. This indicates that these factors apparently contribute more to the weight than the sum of the analyzed chemical constituents. This is consistent with the quite likely hypothesis these hygroscopic components particularly associate a relatively large amount of water. Only one component, residual oil combustion, has a ratio $>1$. This may be due to its larger relative uncertainty. However, it may also indicate that the oxide corrections for metals which are based from soil constituents are oversized for the metals that originate from oil combustion. Other components have a more or less unity factor which corresponds with their chemical nature.

\subsubsection{Sensitivity test}

The plausibility of the assumption a solution with the lowest $Q$ value is the global minimum increases when enough runs with random starting points are performed. Nevertheless there is always a chance the EPA-PMF analysis ends up with a solution associated with a local minimum (Juntto and Paatero, 1994). To assess this problem we have examined 50 converged 7-factor solutions by visually comparing them with the source profiles of the solution with the lowest $Q$ value. The largest collection $(n=40)$ contained solutions comparing well with the solution with the lowest $Q$ value, with a deviation of the $Q$ values less than 100 units. On average, the outcome of the 40 similar profiles remained almost the same providing confidence in the central estimate. Within the ensemble ( $n=40$ ) of solutions variations in apportioned total and species mass was observed. The standard deviation of each mass apportioned to a source is used as an indicator of the stability of the sources. We have estimated the $95 \%$ confidence interval by multiplying the calculated standard deviations with a factor 2 . The apportioned mass for the solution with the lowest $Q$ value, as well as the 95\% confidence interval are given in Table 3. The apportioned mass for both the nitrate-rich and sulphate-rich secondary aerosols is subjected to a larger variation compared to the other profiles. It seems both the CRM and the traffic and resuspended road dust profiles are the most stable, showing only a small amount of variation. We have observed the apportioned total $\mathrm{PM}_{2.5}$ mass for the residual oil combustion (factor 7) might be distributed across other sources depending on the solution. An explanation for this behaviour lies perhaps in the locations of the sites; only two sites (Rotterdam and Schiedam) are in the vicinity of petrochemical industry and marine vessels, both located in the Port of Rotterdam. This would suggest the residual oil combustion is primarily a local phenomenon, with little or no contribution on other sites.

\section{Discussion and conclusions}

Generally, there is a considerable conformity in the chemical composition in the Netherlands. From all the constituents being part of $\mathrm{PM}_{2.5}$ the components related to secondary inorganic aerosol (SIA) are the most dominant (42-48\%). The SIA concentrations are highest at the rural sites, whereas the lowest percentage is found at the urban stations in the Rotterdam area. The second dominant contribution to $\mathrm{PM}_{2.5}$ comes from total carbon matter (TCM): it ranges between 27 and $41 \%$. The lower values were found at rural stations, whereas the maximum was found at the curbside in Rotterdam illustrating the impact of traffic emissions. The other components, i.e. sea salt, crustal material, metals comprise about $5 \%$ each. At days with high concentrations all components are enhanced, except sea salt. Sea salt, which maximizes in marine air masses associated with clean conditions. Except nitrate, the relative contribution of the other components is relatively stable as function of PM concentration. Nitrate concentrations, however, rise disproportionally with respect to $\mathrm{PM}$ indicting its importance in Western Europe (Schaap et al., 2002; Harrison et al., 2004).

The applied mass closure algorithm significantly reduces the not analyzed fraction and the unexplained fraction varies between 0 and 16 percent. The low unexplained fractions at the urban sites was unexpected and are most likely associated with the uncertainty in the TC to TCM conversion for which we used a factor 1.3 (Frank, 2006). Taking the average OC/EC ratio in this study an effective OC to OM factor of 1.6 is used. Literature data vary between 1.2 and 2 and it may very well be possible that the factor varies with lower values near sources and higher values after processing in aged air masses. Furthermore, the uncertain split between EC and OC for different techniques also impacts the magnitude of the corrections between different studies significantly. Hence, the major factor in the mass closure algorithm is also the most uncertain one and may very well be too high for Dutch urban locations.

It could be established that the unexplained mass fraction correlated highest with the SIA mass. A possible reason for the increase of unexplained mass with nitrate may be the amount of water attached to SIA. Ideally this water is removed by pre-heating of the air sample or by conditioning of the filters under dry $(50 \%$ $\mathrm{RH}$ ) circumstances following the reference method (EN 12341, 1998). However heating or drying only partly removes the particle bound water due to hysteresis (e.g. Speer et al., 2003). Speer et al. (2003) report molar ratios around 0.5 for water on ammonium nitrate and ammonium sulphate particles at a $\mathrm{RH}$ of $50 \%$. As such we estimate the amount of water to be $4-5 \%$ of the $\mathrm{PM}_{2.5}$ mass concentration. Such a contribution is possible as it is generally lower than the total unexplained mass. Hence, water is expected to be an important, though not the sole, contributor to the unexplained mass.

By using Positive Matrix Factorization seven sources profiles could be identified for $\mathrm{PM}_{2.5}$. These sources were: Nitrate-rich secondary aerosol; Sulphate-rich secondary aerosol; Traffic and resuspended road dust; Industrial (metal) activities/incineration; Sea spray; Crustal material and Residual oil combustion. Comparing the results of the PMF analysis to the results of the chemical mass closure (Weijers et al., 2011) reveals a very similar picture. The majority of the mass is explained by the secondary inorganic fraction, which confirms the important role of emissions of $\mathrm{NO}_{\mathrm{X}}$, $\mathrm{SO}_{\mathrm{Y}}$ and $\mathrm{NH}_{3}$ in $\mathrm{PM}$ formation. Furthermore, sea salt and crustal material are both identified. Finally, both approaches have a metal group. However, where the chemical mass balance yields the

Table 3

The apportioned mass for the solution with the lowest $Q$ value and the $95 \%$ confidence interval (CI) from the sensitivity test (in $\mu g$ m ${ }^{-3}$ ).

\begin{tabular}{|c|c|c|}
\hline Source & $\begin{array}{l}\text { Contribution } \pm 95 \% \\
\text { confidence interval }\end{array}$ & $\begin{array}{l}\text { Ratio between the sum of all species contributions } \\
\text { associated with this source and the apportioned mass by PMF }\end{array}$ \\
\hline Nitrate-rich secondary aerosol & $7.96 \pm 2.46$ & 0.72 \\
\hline Sulphate-rich secondary aerosol & $4.56 \pm 3.01$ & 0.83 \\
\hline Traffic and resuspended road dust & $1.93 \pm 0.12$ & 0.97 \\
\hline Industrial (metal) activities/incineration & $1.85 \pm 0.61$ & 1.00 \\
\hline Sea spray & $1.22 \pm 0.23$ & 0.67 \\
\hline Crustal material (CRM) & $0.46 \pm 0.09$ & 0.83 \\
\hline Residual oil combustion & $0.17 \pm 0.25$ & 1.26 \\
\hline
\end{tabular}


groups of components, the PMF analysis provides insight in the combinations of components that occur together. For example, it combines soot with components as copper and iron and as such the tail pipe and wear emissions of traffic. Hence, chemical mass balance aims to explain the total mass using information on the occurrence of components, whereas PMF provides insight in common origins of the different components.

A disadvantage of the PMF analysis is that it is based on a linear combination of factors and that it cannot cope with non-linear components. Consequently, the secondary aerosols $\left(\mathrm{SO}_{4}{ }^{2-}, \mathrm{NO}_{3}{ }^{-}\right.$, $\mathrm{NH}_{4}{ }^{+}, \mathrm{OC}$ ) are mainly grouped together in various profiles (sulphate-rich and nitrate-rich secondary aerosol) and no source information is obtained (Viana et al., 2008). The main separation is obtained in the primary components. For example, the tracers for sea salt $(\mathrm{Na}, \mathrm{Mg}, \mathrm{Cl})$ as well as those for mineral dust ( $\mathrm{Al}, \mathrm{Si}, \mathrm{Ti})$ and traffic abrasion $(\mathrm{Cu}, \mathrm{Ba}, \mathrm{Fe})$ are separated from a group that contains a host of different metals and elements. PMF in principle provides an independent and objective analysis of the data. The application of PMF complemented the analysis based on the interpretation of the chemical data. It confirmed independently a large number of species to be a tracer for a specific activity or source.

Common local sources like traffic could be identified in this study. Specific local sources affecting the receptor sites could not be differentiated as all data are combined in the PMF analysis. We feel that a PMF application on datasets obtained within a city or a limited region in the vicinity of different large industries or activities would yield a more effective use of the PMF technique. In our study with locations spread over the whole of the country we identify all the major common source categories. However, these can also be identified based on the chemical composition and the appreciation of the tracers. Exception is the separation of the traffic induced resuspension factor from the total crustal material and the identification of the residual oil combustion. Especially, the latter with its relative high contribution in the Rotterdam area illustrates the potential for the identification of local sources.

Overall, the application of PMF yields a limited number of source profiles for the locations for which detailed date are available. To establish a detailed assessment of the source contributions at a (sub-) sector level and over a certain domain, one relies on the use of chemistry transport models (CTM). As such one can also calculate the apportionment of the major secondary components, i.e. sulphate, nitrate, ammonium. A prerequisite for the application of CTMs is that their performance and model description are satisfactory. The combined use of CTMs and receptor modelling may be a promising way forward as receptor models can be used as a means of evaluation (Dennis et al., 2010) and can help identify potential missing sources in an emission inventory. Recent advances have introduced approaches that integrate receptor modelling methods into CTMs (Koo et al., 2009) and use detailed tracking of emission contributions across space (Wagstrom et al., 2008). Another significant advantage of using CTMs is that they may be used in scenario studies to evaluate the impact of emission abatement strategies on the anthropogenic contribution to ambient PM concentrations.

In short, the application of PMF provides a first step to understanding the sources contribution at a site and complements the analysis based on the interpretation of the chemical data. It confirms independently a large number of species to be a tracer for a specific activity or source. As such, we have obtained more confidence in the interpretation of the dataset at hand.

\section{References}

Ansari, A.S., Pandis, S.N., 1998. Response of inorganic PM to precursor concentrations. Environ. Sci. Technol. 32, 2706-2714.
Baccarelli, A., Pfeiffer, R., Consonni, D., Pesatori, A.C., Bonzini, M., Patterson Jr., D.G. 2005. Handling of dioxin measurement data in the presence of non-detectable values: overview of available methods and their application in the Seveso chloracne study. Chemosphere 60, 898-906.

Brink, H.M. ten, Weijers, E.P., Arkel van, F. Th., de Jonge, D., 2009. Carbon (EC/OC) Concentrations as Derived from Routine PM Measurements in the Netherlands PBL report 500099005 Bilthoven, the Netherlands.

Brown, S.G., Hafner, H.R., 2005. Multivariate Receptor Modeling Workbook. Sonoma Technology, Inc., Petaluma, CA

Brunekreef, B., Holgate, S.T., 2002. Air pollution and health. Lancet 360 (no. 9341), 1233-1242.

Denier van der Gon, H.A.C., Hulskotte, J.H.J., Visschedijk, A.J.H., Schaap, M., 2007. A revised estimate of copper emissions from road transport in UNECE Europe and its impact on predicted copper concentrations. Atmos. Environ. 41 (38), 8697-8710.

Denier van der Gon, H.A.C., Schaap, M., Hendriks, E.C.J., Jozwicka, M., 2010. BOP Thematic Report on Suspended Crustal Material PBL report 500099003 Bilthoven, the Netherlands.

Dennis, R., Fox, T., Fuentes, M., Gilliland, A., Hanna, S., Hogrefe, C., Irwin, J., Rao, S.T., Scheffe, R., Schere, K., Steyn, D., Venkatram, A., 2010. A framework for evaluating regional-scale numerical photochemical modeling systems. Environ. Fluid Mech. vol. 10 (no. 4), 471-489.

Directive 2008/50/EC of the European Parliament and of the Council of 21 May 2008 on ambient air quality and cleaner air for Europe.

Donahue, N.M., Robinson, A.L., Pandis, S.N., 2009. Atmospheric organic particulate matter: from smoke to secondary organic aerosol. Atmos. Environ. 43 (no. 1) 94-106.

Draxler, R.R., Hess, G.D., 1998. An overview of the HYSPLIT_4 modelling system for trajectories, dispersion and deposition. Aust. Meteorol. Mag. 47 (no. 4), 295-308.

EEA, 2007. Europe's Environment. The Fourth Assessment. EEA, Copenhagen.

EN 12341, 1998. Air quality - Determination of the PM 10 Fraction of Suspended Particulate Matter - Reference Method and Field Test Procedure to Demonstrate Reference Equivalence of Measurement Methods.

EN 14907, 2004. Ambient Air Quality: Reference Gravimetric Measurement Method for the Determination of the $\mathrm{PM}_{2.5}$ Mass Fraction of Suspended Particulate Matter.

Escrig Vidal, A., Monfort, E., Celades, I., Querol, X., Amato, F., Minguillón, M.C. Hopke, P.K., 2009. Application of optimally scaled target factor analysis for assessing source contribution of ambient $\mathrm{PM}_{10}$. J. Air Waste Manage. Assoc. 59 (no. 11), 1296-1307.

Fernández-Espinosa, A.J., Ternero-Rodríguez, M., 2004. Study of traffic pollution by metals in Seville (Spain) by physical and chemical speciation methods. Anal Bioanal. Chem. 379 (4), 684-699.

Frank, N.H., 2006. Retained nitrate, hydrated sulfates, and carbonaceous mass in Federal Reference Method fine particulate matter for six eastern cities. J. Air Waste Manag. Assoc. 56, 500-511.

Guo, H., Ding, A.J., So, K.L., Ayoko, G., Li, Y.S., Hung, W.T., 2009. Receptor modeling of source apportionment of Hong Kong aerosols and the implication of urban and regional contribution. Atmos. Environ. 43 (no. 6), 1159-1169.

Harrison, R.M., Jones, A.M., Lawrence, R.G., 2004. Major component composition of $\mathrm{PM}_{10}$ and $\mathrm{PM}_{2.5}$ from roadside and urban background sites. Atmos. Environ. 38, 4531-4538.

Hildemann, L.M., Markowski, G.R., Cass, G.R., 1991. Chemical composition of emissions from urban sources of fine organic aerosol. Environ. Sci. Technol. 25 (4), 744-759.

Hopke, P.K., 1991. An introduction to receptor modeling. Chemometr. Intell. Lab. Syst. 10 (no. 1-2), 21-43.

Hopke, P.K., 2003. A Guide to Positive Matrix Factorization [Online] Available at: http:// people.clarkson.edu/\%7ehopkepk/PMF-Guidance.htm (last visited November 11th, 2010).

Hopke, P.K., Liu, C., Rubin, D.B., 2001. Multiple imputation for multivariate data with missing and below-threshold measurements: time-series concentrations of pollutants in the Arctic. Biometrics 57, 22-33.

Hwang, I., Hopke, P.K., 2006. Comparison of source apportionments of fine particulate matter at two San Jose speciation trends network sites. J. Air Waste Manage. Assoc. 56, 1287-1300.

Ibrahim, J.G., Chen, M.H., Lipsitz, S.R., Herring, A.H., 2005. Missing-data methods for generalized linear models: a comparative review. J. Am. Stat. Assoc. 100 (469) 332-346.

Juntto, S., Paatero, P., 1994. Analysis of daily precipitation data by positive matrix factorization. Environmetrics 5, 127-144.

Kim, E., Hopke, P.K., 2004a. Comparison between conditional probability function and nonparametric regression for fine particle source directions. Atmos. Environ. 38, 4667-4673.

Kim, E., Hopke, P.K., 2004b. Improving source identification of fine particles in a rural northeastern U.S. area utilizing temperature-resolved carbon fractions. J. Geophys. Res. 109, 999.

Kim, E., Hopke, P.K., 2005. Identification of fine particle sources in mid-Atlantic US area. Water Air Soil Pollut. 168 (no. 1-4), 391-421.

Kim, E., Hopke, P.K., 2008. Source characterization of ambient fine particles at multiple sites in the Seattle area. Atmos. Environ. 42 (no. 24), 6047-6056.

Kim, E., Hopke, P.K., Edgerton, E.S., 2003a. Source identification of Atlanta aerosol by positive matrix factorization. J. Air Waste Manage. Assoc. 53, 731-739.

Kim, E., Larson, T.V., Hopke, P.K., Slaughter, C., Sheppard, L.E., Claiborn, C., 2003b. Source identification of $\mathrm{PM}_{2.5}$ in an arid Northwest U.S. City by positive matrix factorization. Atmos. Res. 66, 291-305. 
Kim, E., Hopke, P.K., Pinto, J.P., Wilson, W.E., 2005. Spatial variability of fine particle mass, components, and source contributions during the regional air pollution study in St. Louis. Environ. Sci. Technol. 39 (no. 11), 4172-4179.

Koo, B., Wilson, G.M., Morris, R.E., Dunker, A.M., Yarwood, G., 2009. Comparison of source apportionment and sensitivity analysis in a particulate matter air quality model. Environ. Sci. Technol. 43 (no. 17), 6669-6675.

Laschober, C., Limbeck, A., Rendl, J., Puxbaum, H., 2004. Particulate emissions from on-road vehicles in the Kaisermühlen-tunnel (Vienna, Austria). Atmos. Environ. 38 (14), 2187-2195.

Lee, E., Chan, C.K., Paatero, P., 1999. Application of positive matrix factorization in source apportionment of particulate pollutants in Hong Kong. Atmos. Environ. 33, 3201-3212.

Lee, J.H., Hopke, P.K., Turner, J.R., 2006. Source identification of airborne $\mathrm{PM}_{2.5}$ at the St. Louis-midwest supersite. J. Geophys. Res. 111, 6-12.

Lewis, C.W., Norris, G.A., Conner, T.L., Henry, R.C., 2003. Source apportionment of Phoenix $\mathrm{PM}_{2.5}$ aerosol with the unmix receptor model. J. Air Waste Manage. Assoc. 53, 325-339.

Lippmann, M., Chen, L.-C., 2009. Health effects of concentrated ambient air particulate matter (CAPs) and its components. Crit. Rev. Toxicol. 39 (no. 10), 865-913.

London Air Quality Network, 2008. Saharan Dust Causes Widespread Pollution Episod 23rd-24th January 2008 [Online] Available at: http://www.londonair.org.uk/ london/asp/news.asp\%3fNewsId=SaharanDustJan08 (last visited November 11th 2010).

Manders, A.M.M., Schaap, M., Jozwicka, M., Arkel, F., van Weijers, E.P., Matthijsen, J., 2009. The Contribution of Sea Salt to $\mathrm{PM}_{10}$ and $\mathrm{PM}_{2.5}$ in the Netherlands PBL report 500099004 Bilthoven, the Netherlands.

Marcazzan, G.M., Vaccaro, S., Valli, G., Vecchi, R., 2001. Characterisation of $\mathrm{PM}_{10}$ and $\mathrm{PM}_{2.5}$ particulate matter in the ambient air of Milan (Italy). Atmos. Environ. 35 (27), 4639-4650.

Matthijsen, J., Jimmink, B.A., Leeuw, F.A.A.M., de Smeets, W., 2009. Attainability of $\mathrm{PM}_{2.5}$ Air Quality Standards, Situation for the Netherlands in a European Context PBL report 500099015 Bilthoven, the Netherlands.

Nicolás, J., Chiari, M., Crespo, J., Orellana, I.G., Lucarelli, F., Nava, S., et al., 2008. Quantification of Saharan and local dust impact in an arid Mediterranean area by the positive matrix factorization (PMF) technique. Atmos. Environ. 42 (39), 8872-8882.

Norris, G., Vedantham, R., Wade, K., Brown, S., Prouty, J., Foley, C., 2008. EPA Positive Matrix Factorization (PMF) 3.0 Fundamentals \& User Guide EPA 600/R-08/108.

Olmez, I., Sheffield, A.E., Gordon, G.E., Houck, J.E., Pritchett, L.C., Cooper, J.A., et al., 1988. Compositions of particles from selected sources in Philadelphia for receptor modeling Applications. JAPCA 38 (11), 1392-1402.

Paatero, P., 1999. The Multilinear engine - a table-driven least squares program for solving multilinear problems, including the n-way parallel factor analysis model. J. Comput. Graph. Stat. 8 (4), 854-888.

Paatero, P., Hopke, P.K., 2003. Discarding or downweighting high-noise variables in factor analytic models. Anal. Chim. Acta 490, 277-289.

Paatero, P., Tapper, U., 1994. Positive matrix factorization: a non negative factor model with optimal utilization of error estimates of data values. Environmetrics 5, 111-126.

Paatero, P., Hopke, P.K., Song, X.H., Ramadan, Z., 2002. Understanding and controlling rotations in factor analytic models. Chemometr. Intell. Lab. Syst. 60 253-264.

Pacyna, J.M., Pacyna, E.G., 2001. An assessment of global and regional emissions of trace metals to the atmosphere from anthropogenic sources worldwide. Environ. Rev. 9 (4), 269-298.
Polissar, A.V., Hopke, P.K., Paatero, P., Malm, W.C., Sisler, J.F., 1998. Atmospheric aerosol over Alaska, 2, elemental composition and sources. J. Geophys. Res. 103 (D15), 19,045-19,057.

Ramadan, Z., Eickhout, B., Song, X.H., Buydens, L.M.C., Hopke, P.K., 2003. Comparison of positive matrix factorization and multilinear engine for the source apportionment of particle pollutants. Chemometr. Intell. Lab. Syst. 66, 15-28.

Rubin, D.B., 1976. Inference and missing data. Biometrika 63, 581-592.

Rubin, D.B., 1977. Formalizing subjective notions about the effect of nonrespondents in sample surveys. J. Am. Stat. Assoc. 72, 538-543.

Salminen, R., Batista, M.J., Bidovec, M., Demetriades, A. (Eds.), 2005. Geochemical Atlas of Europe. Part 1: Background Information, Methodology and Maps, ISBN 951-690-921-3, p. 525 (printed) \& 951-690-913-2 (electronic version).

Schaap, M., Denier van der Gon, H.A.C., 2007. On the variability of black smoke and carbonaceous aerosols in the Netherlands. Atmos. Environ. 41 (no. 28), 5908-5920.

Schaap, M., Mueller, K., Brink, H.M. ten, 2002. Constructing the European aerosol nitrate concentration field from quality analysed data. Atmos. Environ. 36 (8), 1323-1335.

Schaap, M., Weijers, E.P., Mooibroek, D., Nguyen, L., 2010. Composition and Origin of Particulate Matter in the Netherlands PBL report 500099007 Bilthoven, the Netherlands

Song, X.H., Polissar, A.V., Hopke, P.K., 2001. Sources of fine particle compositions in the northeastern US. Atmos. Environ. 35, 5277-5286.

Speer, R.E., Edney, E.O., Kleindienst, T.E., 2003. Impact of organic compounds on the concentrations of liquid water in ambient $\mathrm{PM}_{2.5}$. J. Aerosol Sci. 34 (1), 63-77.

Stern, R., Builtjes, P., Schaap, M., Timmermans, R., Vautard, R., Hodzic, A., Memmesheimer, M., Feldmann, H., Renner, E., Wolke, R., Kerschbaumer, A 2008. A model inter-comparison study focussing on episodes with elevated $\mathrm{PM}_{10}$ concentrations. Atmos. Environ. 42, 4567-4588.

Sternbeck, J., Sjödin, A., Andréasson, K., 2002. Metal emissions from road traffic and the influence of resuspension - results from two tunnel studies. Atmos. Environ. 36 (30), 4735-4744.

Thorpe, A., Harrison, R.M., Boulter, P.G., McCrae, I.S., 2007. Estimation of particle resuspension source strength on a major London Road. Atmos. Environ. 41, 8007-8020. doi:10.1016/j.atmosenv.2007.07.006.

Vallius, M., 2005. Characteristics and Sources of Fine Particulate Matter in Urban Air Ph.D. thesis.

Viana, M., Kuhlbusch, T.A.J., Querol, X., Alastuey, A., Harrison, R.M., Hopke, P.K., Winiwarter, W., Vallius, M., Szidat, S., Prévôt, A.S.H., Hueglin, C., Bloemen, H., Wåhlin, P., Vecchi, R., Miranda, A.I., Kasper-Giebl, A., Maenhaut, W., Hitzenberger, R., 2008. Source apportionment of particulate matter in Europe: a review of methods and results. J. Aerosol Sci. 39 (10), 827-849.

Wagstrom, K.M., Pandis, S.N., Yarwood, G., Wilson, G.M., Morris, R.E., 2008. Development and application of a computationally efficient particulate matter apportionment algorithm in a three-dimensional chemical transport model. Atmos. Environ. 42 (22), 5650-5659.

Weijers, E.P., Schaap, M., Nguyen, L., Matthijsen, J., Denier van der Gon, H.A.C., Brink, H.M. ten, Hoogerbrugge, R., 2011. Anthropogenic and natural constituents in particulate matter in the Netherlands. Atmos. Chem. Phys. 11, 2281-2294. doi:10.5194/acp-11-2281-2011.

Xie, Y., Berkowitz, C.M., 2006. The use of positive matrix factorization with conditional probability functions in air quality studies: an application to hydrocarbon emissions in Houston, Texas. Atmos. Environ. 40, 3070-3091.

Yang, X., Belin, T.R., Boscardin, W.J., 2005. Imputation and variable selection in linear regression models with missing covariates. Biometrics 61 (2), 498-506. 